\title{
Graphite and PMMA as pore formers for thermoplastic extrusion of porous 3Y-TZP oxygen transport membrane supports
}

Bjørnetun Haugen, Astri; Gurauskis, Jonas; Kaiser, Andreas; Søgaard, Martin

Published in:

European Ceramic Society. Journal

Link to article, DOI:

10.1016/j.jeurceramsoc.2016.10.001

Publication date:

2016

Document Version

Peer reviewed version

Link back to DTU Orbit

Citation (APA):

Bjørnetun Haugen, A., Gurauskis, J., Kaiser, A., \& Søgaard, M. (2016). Graphite and PMMA as pore formers for thermoplastic extrusion of porous 3Y-TZP oxygen transport membrane supports. European Ceramic Society. Journal, 37(3), 1039-1047. https://doi.org/10.1016/j.jeurceramsoc.2016.10.001

\section{General rights}

Copyright and moral rights for the publications made accessible in the public portal are retained by the authors and/or other copyright owners and it is a condition of accessing publications that users recognise and abide by the legal requirements associated with these rights.

- Users may download and print one copy of any publication from the public portal for the purpose of private study or research.

- You may not further distribute the material or use it for any profit-making activity or commercial gain

- You may freely distribute the URL identifying the publication in the public portal 


\title{
Graphite and PMMA as pore formers for thermoplastic extrusion of porous 3Y-TZP oxygen transport membrane supports
}

Astri Bjørnetun Haugen, ${ }^{\mathrm{a} *}$ Jonas Gurauskis, ${ }^{\mathrm{a}, \mathrm{b}}$ Andreas Kaiser ${ }^{\mathrm{a}}$ and Martin Søgaard ${ }^{\mathrm{a}, \mathrm{c}}$

a Department of Energy Conversion and Storage, Technical University of Denmark, Frederiksborgvej 399, DK-4000 Roskilde, Denmark

${ }^{\mathrm{b}}$ Current address: Æneam ApS, DK-2450 København, Denmark

${ }^{c}$ Current address: Meneta Advanced Shims Technology A/S, Kirkegyden 52, DK-5270 Odense N, Denmark

* Corresponding author. Phone: +45 215609 19, Fax +45 458817 99, E-mail: ahua@dtu.dk

\begin{abstract}
A gas permeable porous support is a crucial part of an asymmetric oxygen transport membrane (OTM). Here, we develop feedstocks for thermoplastic extrusion of tubular, porous 3Y-TZP (partially stabilized zirconia polycrystals, $\left.\left(\mathrm{Y}_{2} \mathrm{O}_{3}\right)_{0.03}\left(\mathrm{ZrO}_{2}\right)_{0.97}\right)$ ) ceramics, using graphite and/or polymethyl methacrylate (PMMA) as pore formers. The influence of pore former content and type, 3Y-TZP particle size and support sintering temperature on the microstructure, porosity and gas permeability were studied. Using at least 40 vol\% pore former, consisting of graphite and PMMA in the volume ratio $2: 1$, tubes with gas permeability exceeding the target of $10^{-14} \mathrm{~m}^{2}$ are obtained. In the temperature range $1250-1400^{\circ} \mathrm{C}$ the support gas permeability is insensitive to the sintering temperature, and the feedstocks shrink more than $15 \%$ during sintering, making them ideal for cosintering with functional OTM layers. This demonstrates the suitability of thermoplastic extrusion for fabrication of porous 3Y-TZP OTM supports, or for other technologies requiring porous ceramics.
\end{abstract}

\section{Keywords}

Porosity, gas permeability, thermoplastic extrusion, oxygen transport membranes, YSZ 


\section{Introduction}

Pure oxygen gas supplied by ceramic oxygen transport membranes (OTM) can facilitate more efficient gasification processes and easier $\mathrm{CO}_{2}$ capture and storage. ${ }^{1}$ The oxygen flux is inversely proportional to the thickness of the membrane, ${ }^{2}$ and thin OTMs are therefore necessary to obtain commercially interesting oxygen fluxes. An asymmetric OTM design is therefore common, where the active membrane is reduced to $10-20 \mu \mathrm{m}$ in thickness and supported on a $0.5-1 \mathrm{~mm}$ thick porous substrate necessary for mechanical integrity. ${ }^{3}$ This support must in addition to good mechanical properties also have a sufficient gas permeability to avoid concentration polarization losses. A tubular OTM design is generally preferred due to simpler sealing and higher tolerance to thermal gradients than planar modules ${ }^{1}$. This work demonstrates how such support structures can be prepared by thermoplastic extrusion through the optimization of the extrusion feedstocks.

Thermoplastic feedstocks differ from the more common solvent-based feedstocks ${ }^{4,5}$ in the way that they obtain their plasticity from warm thermoplastic polymers rather than a binder and a solvent. The thermoplastic feedstocks are compounded and extruded above the softening temperature of the polymer, and cool and harden immediately after extrusion. This process provides many advantages, for example: ${ }^{6}$ 1) high green extrudate strength, 2) complex and thin-walled extrudates 3) low abrasion and wear of the equipment and 4) no complex drying step. A disadvantage is, however, the more complex de-binding process due to the large volume of polymer that must be removed. Thermoplastic feedstocks are commonly used for injection molding, and have also been used to extrude dense ceramics, ${ }^{7,8}$ but are rarely studied for extrusion of porous ceramics ${ }^{9}$.

So far, thermoplastic feedstocks that can provide porous ceramic support tubes of sufficient gas permeability and mechanical strength (>50 MPa) in a multilayer co-firing process for asymmetric OTM fabrication has not been reported. The required support gas permeability depends highly on the membrane material and operation conditions, ${ }^{10}$ but as a general guideline for a $1 \mathrm{~mm}$ thick support the Darcy permeability coefficient $k$ should exceed $10^{-14} \mathrm{~m}^{2}$. The gas permeability depends on the volume fraction of porosity $(\phi)$ and the pore diameter $\left(D_{p}\right)$ :

$$
k=\phi D_{p}^{2} / 32
$$

for the case of a simplified model with parallel pore channels (capillary permeability) ${ }^{11}$ Real porous structures with a more tortuous pore network will therefore have a lower permeability than predicted from Eqn.1. Still, Eqn. 1 can provide guidelines for the material engineering; e.g. that 
porosity above $40 \%$ and pore size above $1 \mu \mathrm{m}$ should be aimed for to obtain gas permeability in the range of $10^{-14} \mathrm{~m}^{2}$.

Sufficiently porous tubes have been obtained by solvent-based extrusion using partial sintering of coarse powders. ${ }^{12}$ Our approach to introduce porosity in our thermoplastic feedstocks is using large pyrolyzable pore formers, combined with fine ceramic particles of high sintering activity. This allows co-sintering of the tubes with deposited thin films containing powders of similar sintering activity, without shrinkage mismatch between the layers. ${ }^{13}$ For this, at least $15 \%$ linear shrinkage in the support tube is desired during sintering. The selected pore formers should be as isometric as possible, since anisometric pore formers will be aligned with the extrusion direction, ${ }^{14,15}$ and limit the desired pore connectivity in the radial direction. The high polymer content in thermoplastic feedstocks also limits the choice of pore formers; a completely polymer-based pore former might not be suitable due to the large gas volume developed if the pore former decomposes in the temperature range of the thermoplastic polymers. Furthermore, the introduction of the pore former should not compromise the feedstock's plasticity and extrudability. Previous work has shown that thermoplastic feedstocks with up to 20 vol\% graphite pore former could be extruded, yielding $\mathrm{MgO}$ support tubes with $42.5 \%$ porosity and $4.7 * 10^{-16} \mathrm{~m}^{2}$ gas permeability. ${ }^{9}$ Pore former volumes up to 27 vol\% was possible by combining spherical polymethyl methacrylate (PMMA) and graphite pore formers, increasing the gas permeability to $4.5^{*} 10^{-15} \mathrm{~m}^{2}$ for MgO, but only demonstrated with small disc samples. ${ }^{16}$ This work continues exploring this combination of PMMA and spherical type of graphite as pore formers in thermoplastic feedstocks, but now for extrusion of porous 3Y-TZP $\left(\left(\mathrm{Y}_{2} \mathrm{O}_{3}\right)_{0.03}\left(\mathrm{ZrO}_{2}\right)_{0.97}\right)$ tubes. This composition was chosen due to its transformation toughening mechanism, which should provide a support with high fracture resistance. We show how the pore former type and content - as well as the size of the 3Y-TZP powder and the sintering temperature affect the microstructure and gas permeability.

\section{Experimental}

\subsection{Thermoplastic feedstock preparation}

Thermoplastic feedstocks were prepared with different amounts of ceramic powder, polymer and pore formers as shown in Fig. 1. The ceramic powder was $\left(\mathrm{Y}_{2} \mathrm{O}_{3}\right)_{0.03}\left(\mathrm{ZrO}_{2}\right)_{0.97}(3 \mathrm{Y}-\mathrm{TZP})(40 \mathrm{~nm}$ primary particle size, product TZ-3Y-E, Tosoh, Japan) coated with 5.36 wt\% stearic acid (Sigma- 
Aldrich, USA) as a surfactant. The stearic acid amount was calculated ${ }^{17,18}$ to provide 1.5 monolayer coverage for sufficient wetting without excess stearic acid. For one feedstock, a slightly coarser 3YTZP powder (90 nm primary particle size, product TZ-3YS-E, Tosoh, Japan) was used. The polymer system, based on thermoplastic feedstocks for injection moulding, ${ }^{19}$ consisted of an ethylene-vinyl acetate copolymer (Elvax $@$ 250, DuPont, USA) as the main binder and paraffin wax (melting point $53-57{ }^{\circ} \mathrm{C}$, Sigma-Aldrich, USA) as a secondary binder/lubricant, always in the volume ratio 2:1. The pore former consisted of graphite and/or polymethyl methacrylate (PMMA), both shown in Fig. 1. The graphite was a "spherical" type with $d_{v 50}$ of $18 \mu \mathrm{m}$ (FormulaBT SLA1518, Superior Graphite, USA), the PMMA a cross-linked (to avoid softening prior to decomposition) and polydisperse type with a $\mathrm{d}_{\mathrm{V} 50}$ of $9 \mu \mathrm{m}$ (MR-10G, Esprix, USA).
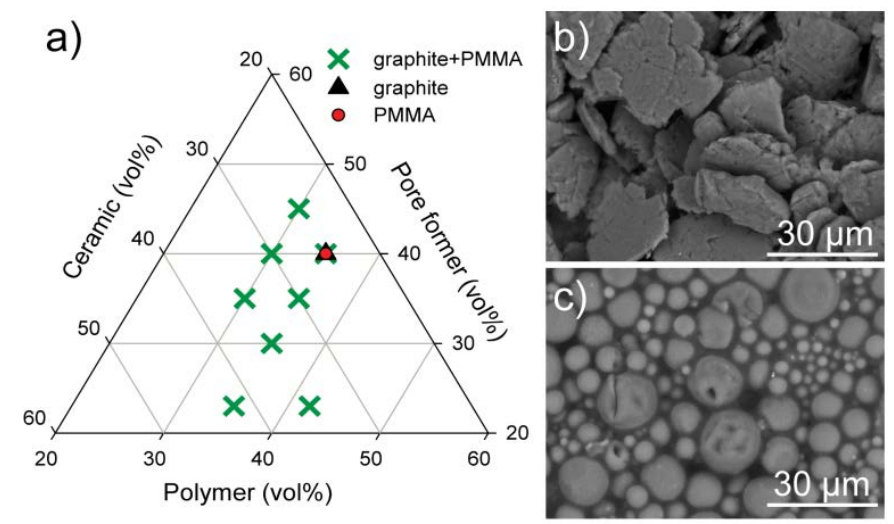

Fig. 1. a) Ternary composition diagram of the different thermoplastic feedstocks studied for the preparation of porous $3 \mathrm{Y}-\mathrm{TZP}$. The ceramic is $3 \mathrm{Y}-\mathrm{TZP}$, the polymers are Elvax® and paraffin wax, and the pore former is graphite or PMMA, or a mixture of both (indicated with different symbols). Micrographs of the two pore formers: b) the spherical graphite and c) the PMMA, are shown on the right.

Warm pressing has previously been found to provide similar microstructure as extrusion for thermoplastic feedstocks, ${ }^{8}$ and was therefore used as an initial shaping method during the screening of a large number of feedstocks. Feedstocks of $55 \mathrm{ml}$ were mixed and compounded at $110-115{ }^{\circ} \mathrm{C}$ (Kneader 50N, Brabender, Germany), warm pressed to 1-2 mm thickness and cut into $24 \mathrm{~mm}$ diameter discs. A few selected batches (presented in Section 3.5) were scaled up to $500 \mathrm{ml}$ in a larger kneader (Type BK20, Linden, Germany) and extruded into tubes (14 mm outer diameter, 1 mm thickness, length $>300 \mathrm{~mm}$ ) at $110{ }^{\circ} \mathrm{C}$ using a single screw extruder (Model 19/20DN, Brabender, Germany). Sintering of all samples was performed in air with a slow heating rate to 
avoid binder and pore former decomposition defects: $10^{\circ} \mathrm{C} / \mathrm{h}$ to $250{ }^{\circ} \mathrm{C}$ ( $2 \mathrm{~h}$ hold), $10{ }^{\circ} \mathrm{C} / \mathrm{h}$ to 400 ${ }^{\circ} \mathrm{C}$ (2 h hold), $10^{\circ} \mathrm{C} / \mathrm{h}$ to $650{ }^{\circ} \mathrm{C}$ (2 h hold), $30^{\circ} \mathrm{C} / \mathrm{h}$ to the sintering temperature $\left(1250-1400{ }^{\circ} \mathrm{C}\right)(2$ $\mathrm{h}$ hold) and finally cooling at $100^{\circ} \mathrm{C} / \mathrm{h}$.

All samples are named as "composition” (vol\% pore former / vol\% ceramic / vol\% polymers)-“pore former” (G for graphite, P for PMMA, GP for both (volume ratio 2:1 unless otherwise stated))“sintering temperature" $\left({ }^{\circ} \mathrm{C}\right)$. For example, sample 40/25/35-GP-1300 has the overall composition $40 \mathrm{vol} \%$ pore former, 25 vol\% $3 \mathrm{Y}$-TZP powder and 35 vol\% polymers), the pore formers are graphite and PMMA in the ratio 2:1, and is sintered at $1300{ }^{\circ} \mathrm{C}$. The coarser 3Y-TZP powder is used in samples marked with a "c” at the end, e.g. 40/25/35-GP-1300-c.

\subsection{Characterization}

Dimensions and weight of green and sintered samples were used to calculate the total density/porosity relative to the theoretical density of each green feedstock or 3Y-TZP, as well as the linear shrinkage after sintering. Hg porosimetry (Poremaster@ GT, Quantachrome Instruments, USA) was used to measure open porosity and pore size distribution of sintered samples. The microstructure of polished sample cross-sections was studied by SEM (TM 3000, Hitachi, Japan). The gas flow through the samples upon application of a pressure gradient was used to calculate the Darcy gas permeability coefficient, $k$ :

$$
k=\frac{j \mu}{\nabla p}
$$

, where $j$ is the gas flux $\left[\mathrm{m}^{3} / \mathrm{m}^{2} \mathrm{~s}\right], \mu[\mathrm{Pa} \mathrm{s}]$ is the viscosity of the gas, and $\nabla p$ is the pressure gradient over the sample $[\mathrm{Pa} / \mathrm{m}]$. The measurements were performed with $\mathrm{N}_{2}$ at room temperature and a total pressure difference of $200 \mathrm{kPa}$.

\section{Results and discussion}

For all samples the shrinkage, porosity, pore size, gas permeability and the torque during compounding are summarized in Table A.1 in the Appendix. The general observed trends within all the studied samples will be presented in the following subsections. 


\section{1 Influence of amount of pore former on 3Y-TZP support properties}

Starting with the previously tested ${ }^{16}$ 2:1 mixture of graphite and PMMA as the pore former, we first tried to optimize the relative amounts of 3Y-TZP powder, thermoplastic polymers and pore former in the feedstocks. The feedstock should contain enough pore formers for sufficient porosity, and at the same time enough polymers to provide defect-free and form-stable tubes. Several feedstocks with different amounts of pore formers (PMMA and graphite), 3Y-TZP powder and thermoplasts were studied (green crosses in Fig. 1). The torque during kneading, indicative of the feedstock's viscosity, generally increased with the pore former content (Table A.1), but none of the feedstocks appeared too low in plasticity for extrusion (causing too high torque or pressure for the extruder). On the other hand, an upper limit for the polymer content was identified to be between 35 and 42 vol\%, since feedstock 23/35/42-GP with 42 vol\% polymer appeared too low in viscosity (torque 2.5 $\mathrm{Nm}$ ) for extrusion (resulting in collapse or deformation of the tube after leaving the extruder).

The effect of the pore former content and the characteristic microstructure obtained with PMMA and graphite as pore formers are demonstrated by samples 23/42/35-GP-1300 and 45/25/30-GP-1300 in Fig. 2a-b. Both samples display large (5-15 $\mu \mathrm{m})$ “extrinsic” pores, formed by the similarly sized and shaped pore formers. The regular, circular pores are from PMMA, and the more irregular, oval pores with a preferential horizontal orientation (normal to the warm pressing axis) are from graphite, consistent with previous work on PMMA and graphite pore formers in thermoplastic feedstocks. ${ }^{16}$ Both samples also contain smaller $(<1 \mu \mathrm{m})$, “intrinsic” pores within the ceramic matrix. With increasing pore former content: i) the total pore volume increases, and ii) the graphite pores appear more fibrous. Increased overall pore former content is the natural explanation for the increased porosity. An increasing amount of pore formers also decreases the plasticity of the feedstock, making it less deformable during warm pressing. This increases the load on the pore formers, such that the platelet-shaped (anisometric) graphite aligns more perpendicular to the warm pressing axis, and the pore structure appears more fibrous in the two-dimensional, cross-sectional micrograph (Fig. 2b). The pores from the PMMA are not affected, due to the spherical (isometric) shape of the PMMA particles. 


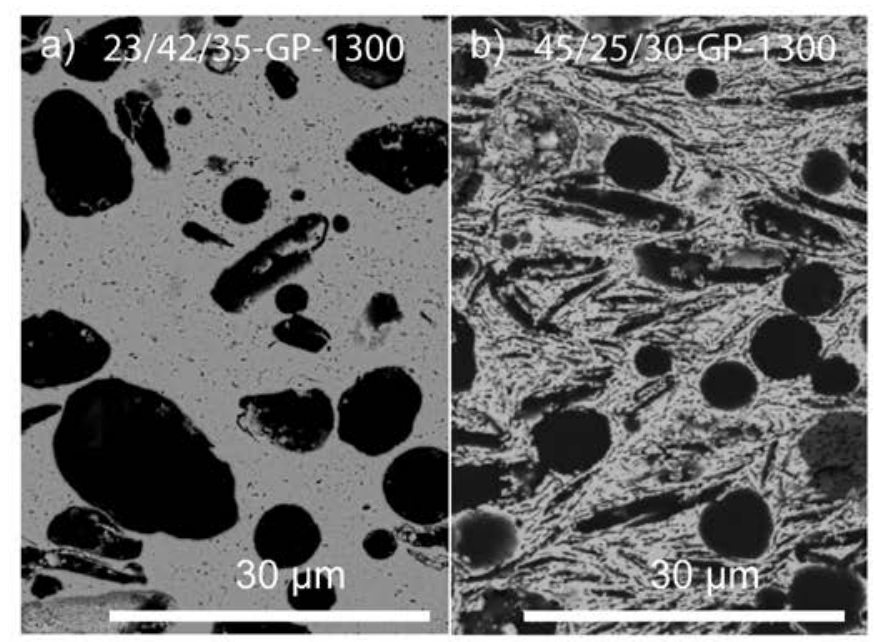

c)

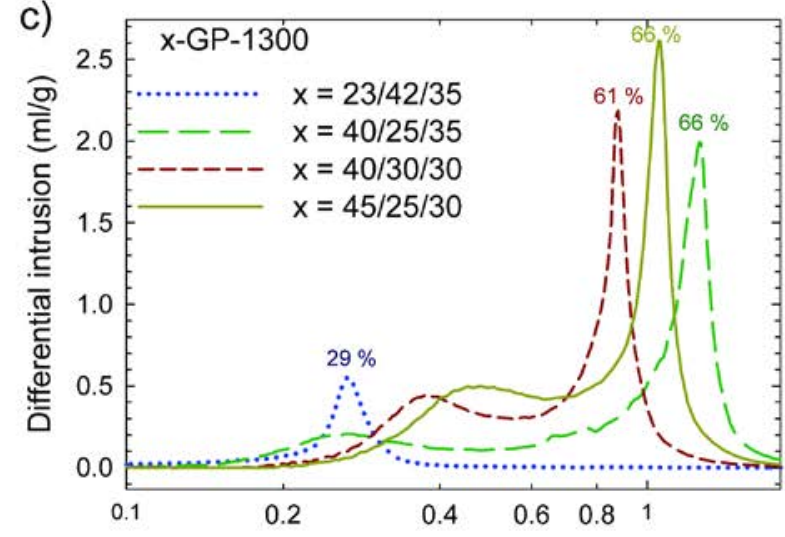

d)

Pore diameter $(\mu \mathrm{m})$

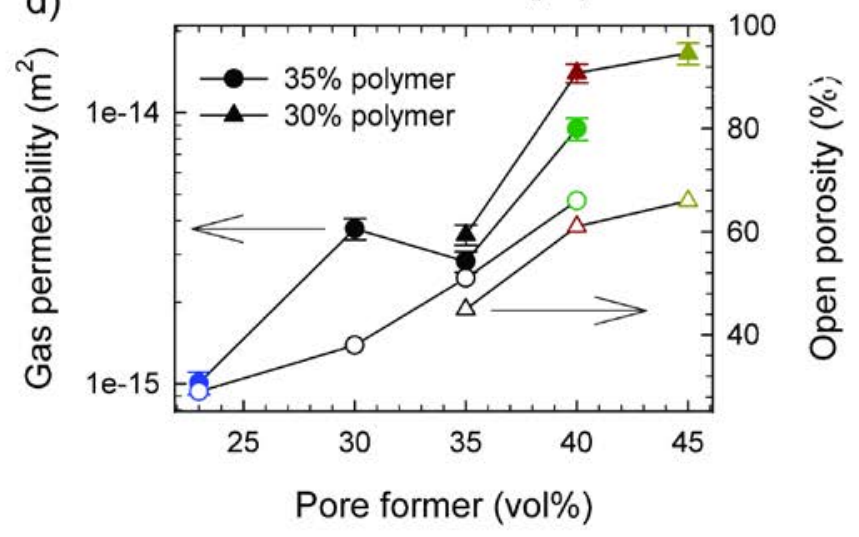

Fig. 2. Effect of increasing the pore former content on microstructure, porosity and gas permeability. Polished cross-section micrographs of two samples with different amount of pore former: a) 23/42/35-GP-1300 (23 \% pore former) and b) 45/25/30-GP-1300 (45 \% pore former). c) Porosimetry of selected samples with varying amount of pore former. The sample's open porosity is written above each peak. d) Gas permeability (filled symbols) and open porosity (open symbols) after sintering at $1300{ }^{\circ} \mathrm{C}$ vs. amount of pore former, split into series with constant amount of polymer. The samples presented in Fig. 2c are plotted with the same colors here. 
The effect of pore former content on the porosity is also visible by Hg porosimetry. From the selected pore size distribution curves in Fig. 2c, we can see that both the pore size and the open porosity are highest for the samples with $>40$ vol\% pore former. Their pore size distribution is bimodal, with the strongest peak around $1 \mu \mathrm{m}$ and the weaker peak/shoulder at 0.3-0.5 $\mu \mathrm{m}$. As $\mathrm{Hg}$ porosimetry measures the narrowest section of the connected pore channels, ${ }^{20}$ it is evident that the larger extrinsic pores with a diameter of about $10 \mu \mathrm{m}$ (Fig. 2a-b) are connected by "bottlenecks" of smaller diameter (about $1 \mu \mathrm{m}$ ). The widening of these bottlenecks with increased pore former content (Fig. 2c) suggests more overlapping volume of the extrinsic pores.

Fig. $2 \mathrm{~d}$ shows how the porosity and the gas permeability increase with the pore former content. A pore former content of more than 35 vol\%, resulting in a total open porosity of more than $50 \%$, is required to achieve sufficient permeability (above $10^{-14} \mathrm{~m}^{2}$ ). As expected, the highest gas permeability was observed in the samples with the highest loading of pore former (45/20/35-GP1300). Decreased polymer content appears in some cases to increase the permeability. The reason for this is not clear, but it is possible that the high pore former and low polymer content complicates the kneading process and causes a “drier” and less homogeneous feedstock of lower packing density. The lower packing density therefore increases the intrinsic porosity, which ultimately increases the permeability.

\subsection{Influence of type of pore former on 3Y-TZP support properties}

By increasing the amount of the 2:1 graphite to PMMA pore former in the feedstock to above $35 \%$, gas permeability above $10^{-14} \mathrm{~m}^{2}$ could be obtained. We then tried to further optimize the most suitable feedstocks by varying the type of pore former: only graphite, only PMMA, or graphite and PMMA mixed in different volume ratios.

Replacing the 2:1 graphite:PMMA pore former in composition 40/25/35 with pure PMMA resulted in a very plastic, low viscosity feedstock (torque of $3.5 \mathrm{Nm}$ ), which appeared unsuitable for extrusion. On the other hand, using pure graphite caused a slightly higher viscosity (torque of $11.0 \mathrm{Nm}$ ) compared to the 2:1 mixture of graphite and PMMA (torque of 6.9 Nm). The pore former type's influence on the feedstock microstructure is shown in Fig. 3 a-c. The sample made from graphite and PMMA (40/25/35-GP-1300) has a similar microstructure as the other samples made with graphite and PMMA discussed in Section 3.1. The porosity using only graphite (40/25/35-G-1300) appears to be of the same magnitude as with graphite+PMMA, but the pores 
appear very fibrous. This is attributed to the lower plasticity from the high graphite content in the feedstock. Pure PMMA as pore former (40/25/35-P-1300) gives very uniform, spherical pores, but the porosity appears lower and the pores seem mostly isolated.
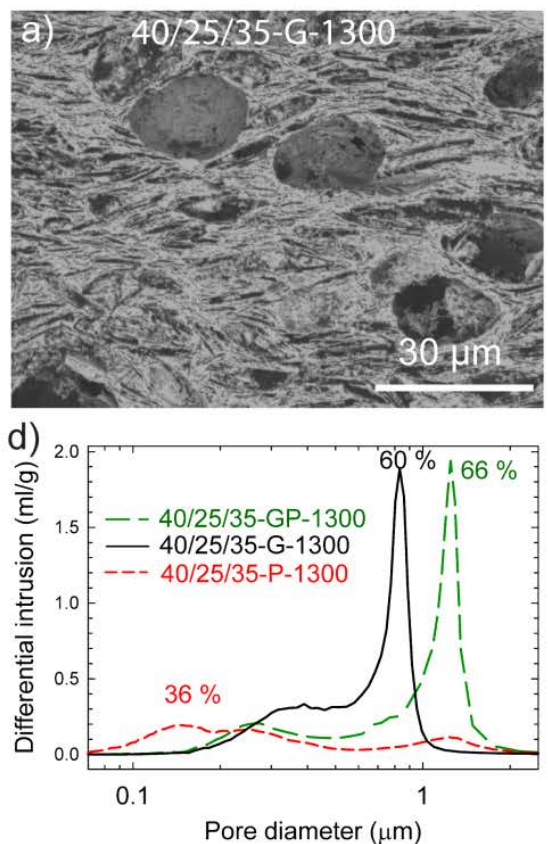

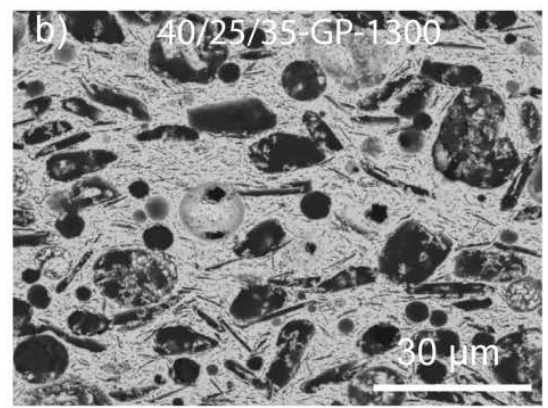

e)

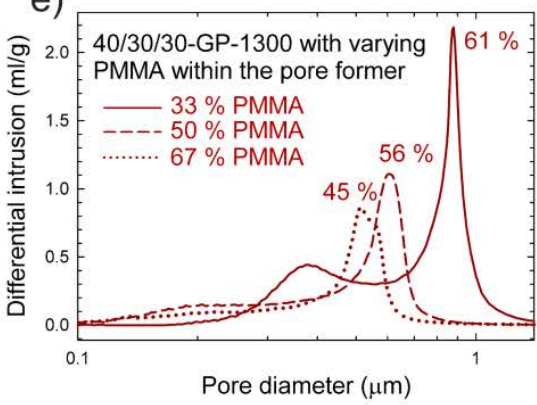

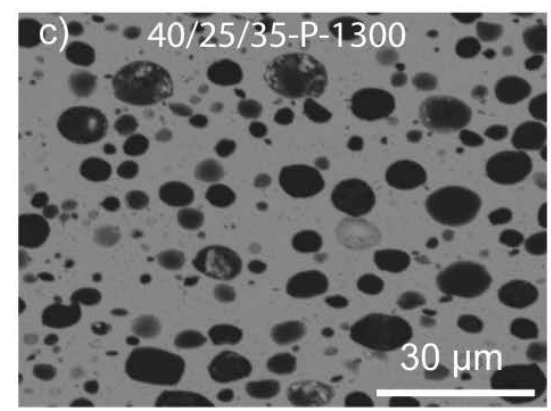

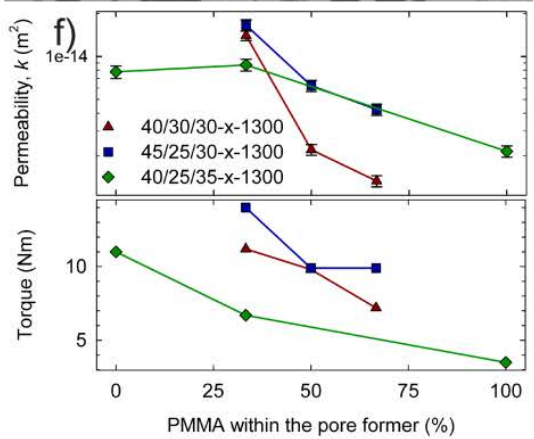

Fig. 3. Effect of type of pore former. a-c) Micrographs of polished cross-sections of composition 40/25/35 sintered at $1300{ }^{\circ} \mathrm{C}$ with the same vol\% of either graphite and PMMA (2:1), graphite or PMMA as pore former. d) Porosimetry of the samples in a-c). The sample's open porosity is written above its peak. e) Porosimetry of samples with varying graphite:PMMA ratio, with the sample's open porosity written above its peak. f) Permeability and torque during mixing vs. fraction of PMMA within the pore former, for three different overall feedstock compositions.

The SEM microstructures correlate well with the Hg porosity measurements. Fig. 3d shows how pure PMMA as the pore former (40/25/35-P-1300) results in very low open porosity and very small pore bottlenecks (36 \% and a $\mathrm{d}_{\mathrm{v} 50}$ of $0.29 \mu \mathrm{m}$ ). Samples from this feedstock also appear to have a large amount of closed porosity; while the average closed porosity (estimated as the difference between the dimensions and mass-based total porosity and the porosimetry-based open porosity) is $5 \%$, the closed porosity is $19 \%$ for 40/25/35-P-1300 and $17 \%$ for $40 / 25 / 35-\mathrm{P}-1400$. Pure graphite as pore former (40/25/35-G-1300) results in a bimodal pore structure (60 \% and a $\mathrm{d}_{\mathrm{v} 50}$ of $0.75 \mu \mathrm{m}$ ), similar to the graphite and PMMA samples in Fig. 2. The graphite and PMMA combination gives the largest porosity and pore size (66 \% and a $d_{v 50}$ of $1.13 \mu \mathrm{m}$ ). Furthermore, 
increasing the PMMA content in the graphite:PMMA mixture at constant total amount of pore former, the pore size and porosity decreases (Fig. 3e).

Fig. 3f compares the torque during preparation of three different feedstocks and the resulting gas permeability of the sintered 3Y-TZP support structures as function of the amount of PMMA in the pore former mixture. Both torque and gas permeability decrease with the amount of PMMA. Nevertheless, graphite and PMMA in a ratio of 2:1 seem to provide the best combination of high gas permeability and suitable torque for feedstock preparation (Fig. 3f).

\subsection{Effect of sintering temperature on 3Y-TZP support properties}

All samples presented so far have been sintered at $1300{ }^{\circ} \mathrm{C}$. This temperature might not be the optimal, neither with respect to the gas permeability in the porous support, nor for a co-sintering with OTM functional layers. The sintering temperature of the feedstock was therefore varied, and its influence of the pore size distribution (Fig 4a), gas permeability and shrinkage (Fig. 4b), and microstructure (Fig. 4c-d), is described in this section.

The porosimetry plots (Fig. 4a) demonstrate the trend of increasing pore size and decreasing open porosity decreases with increased sintering temperature. Furthermore, the pore size distribution changes from bimodal to a more unimodal distribution after sintering above $1300{ }^{\circ} \mathrm{C}$; e.g. in sample 40/25/35-GP the peak around $0.25 \mu \mathrm{m}$ in the pore size distribution is removed after sintering at $1400^{\circ} \mathrm{C}$.
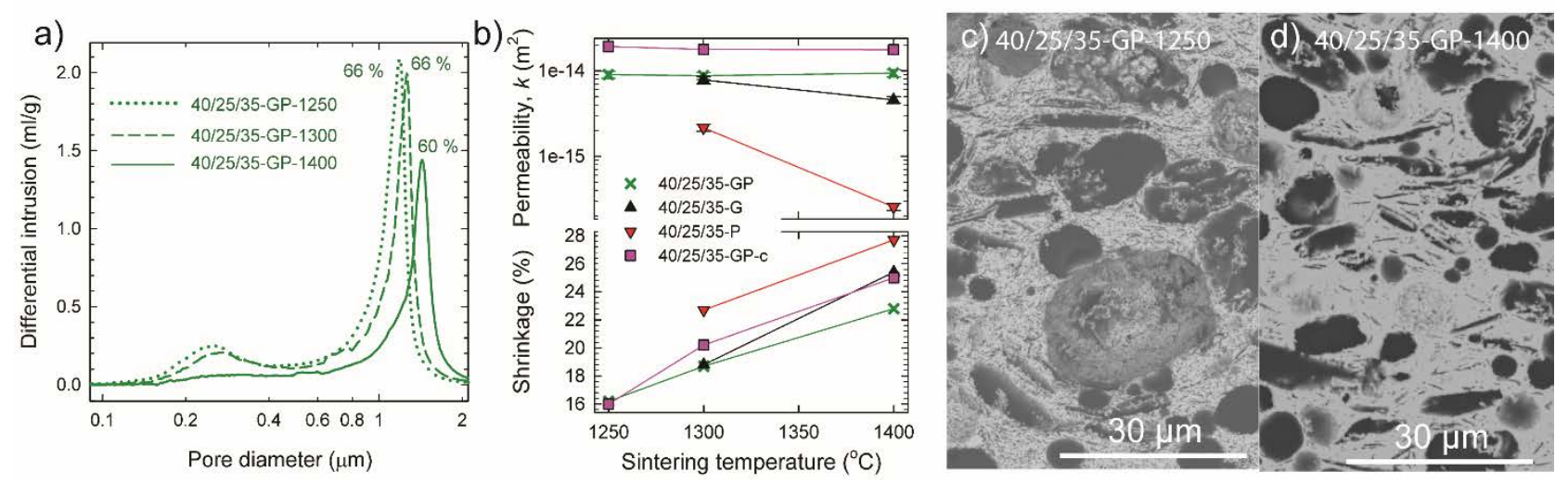

Fig. 4. Effect of sintering temperature on microstructure and properties of porous 3Y-TZP support structures with a mixture of graphite and PMMA (ratio graphite:PMMA = 2:1). a) Porosimetry of 40/25/35-GP sintered at 1250,1300 and $1400{ }^{\circ} \mathrm{C}$. The open porosity is written above each sample. b) Effect of sintering temperature on the gas permeability and linear shrinkage for selected 
feedstocks. The standard deviation in the measured shrinkage is less than $1 \%$ for all samples. c) Micrograph of $40 / 25 / 35-G P$ sintered at $1250^{\circ} \mathrm{C}$ and d) the same feedstock sintered at $1400{ }^{\circ} \mathrm{C}$.

The shrinkage during sintering increases significantly with the sintering temperature (Fig. 4b), typically from $\sim 16 \%$ at $1250{ }^{\circ} \mathrm{C}$ to $\sim 23 \%$ at $1400{ }^{\circ} \mathrm{C}$. The largest shrinkage at all temperatures is found for feedstocks 23/35/42-GP (27 \%) and 40/25/35-P (23-28\%) (Table A.1), where either the content of polymer or PMMA is large. Compared to the distinct effect of sintering temperature on the porosity and the shrinkage, the effect is less pronounced for the gas permeability (Fig. 4b). For some feedstocks, the permeability increases slightly from samples sintered at 1250 to $1300{ }^{\circ} \mathrm{C}$, and then decreases slightly again after sintering at $1400{ }^{\circ} \mathrm{C}$ (Table A.1), but the effect of temperature is mostly insignificant. A drastic decrease is only observed in 40/25/35-P, where the gas permeability drops an order of magnitude from 1300 to $1400^{\circ} \mathrm{C}$.

All feedstocks display the same microstructural changes with sintering temperature as shown for feedstock 40/25/35-GP sintered at 1250 and $1400{ }^{\circ} \mathrm{C}$ (Fig. 4c-d). The extrinsic pores appear unaffected, while the intrinsic pores that are very visible after sintering at $1250{ }^{\circ} \mathrm{C}$ have almost completely disappeared after sintering at $1400{ }^{\circ} \mathrm{C}$. The microstructural effects of the sintering temperature can be rationalized by Ostwald ripening and shrinkage. With increasing temperature the smaller, intrinsic pores in the 3Y-TZP matrix are consumed (first) during densification. The larger, extrinsic pores are too large to be removed during sintering. In addition, the shrinkage of the ceramic matrix brings the pores in closer contact, enlarging the pore necks between them. The fast removal of the intrinsic pores can explain the dramatic decrease in the permeability of the sample with only PMMA as pore former, because in this case the spherical, extrinsic pores get isolated. The formation of larger pores and lower porosity with increased sintering temperature contribute oppositely to the gas permeability (ref Eqn. 1). It is therefore not surprising that the gas permeability is less affected by the sintering temperature than the other factors described before (amount and type of pore former).

\subsection{Effect of 3Y-TZP particle size on 3Y-TZP support properties}

In the previous sections we have tried to increase the permeability of the 3Y-TZP supports by increasing the pore former fractions in the feedstock, varying the pore former type, and adjusting the sintering temperature. The intrinsic porosity appears to be important for the gas permeability of the porous 3Y-TZP structure. Here, we investigate if using a coarser 3Y-TZP raw powder can increase the intrinsic porosity and hence improve the gas permeability without decreasing the 
sintering shrinkage too much. The SEM micrographs of 40/25/35-GP-1250 and 40/25/35-GP-1250c (coarser 3Y-TZP) (Fig. 5a-b) show the extrinsic pores' morphology to be unaffected by the 3YTZP particle size, while the intrinsic pores appear to increase as the particle size increases. The porosimetry plots (Fig. 5c) show a larger pore size and more unimodal size distribution for the sample with coarser 3Y-TZP powder. This is similar to the effect of increased sintering temperature on pore size distribution and total porosity, except that in this case the total porosity does not decrease. This indicates that the coarser powder provides wider pore channels that better connect the extrinsic pores at comparable shrinkage and densification. As a result of the enlargement of bottleneck pores, a 3Y-TZP structure prepared from coarser raw powder increases the gas permeability by a factor of two compared to the finer powder (Fig. 4b), without compromising the shrinkage during sintering (Fig. 4b).
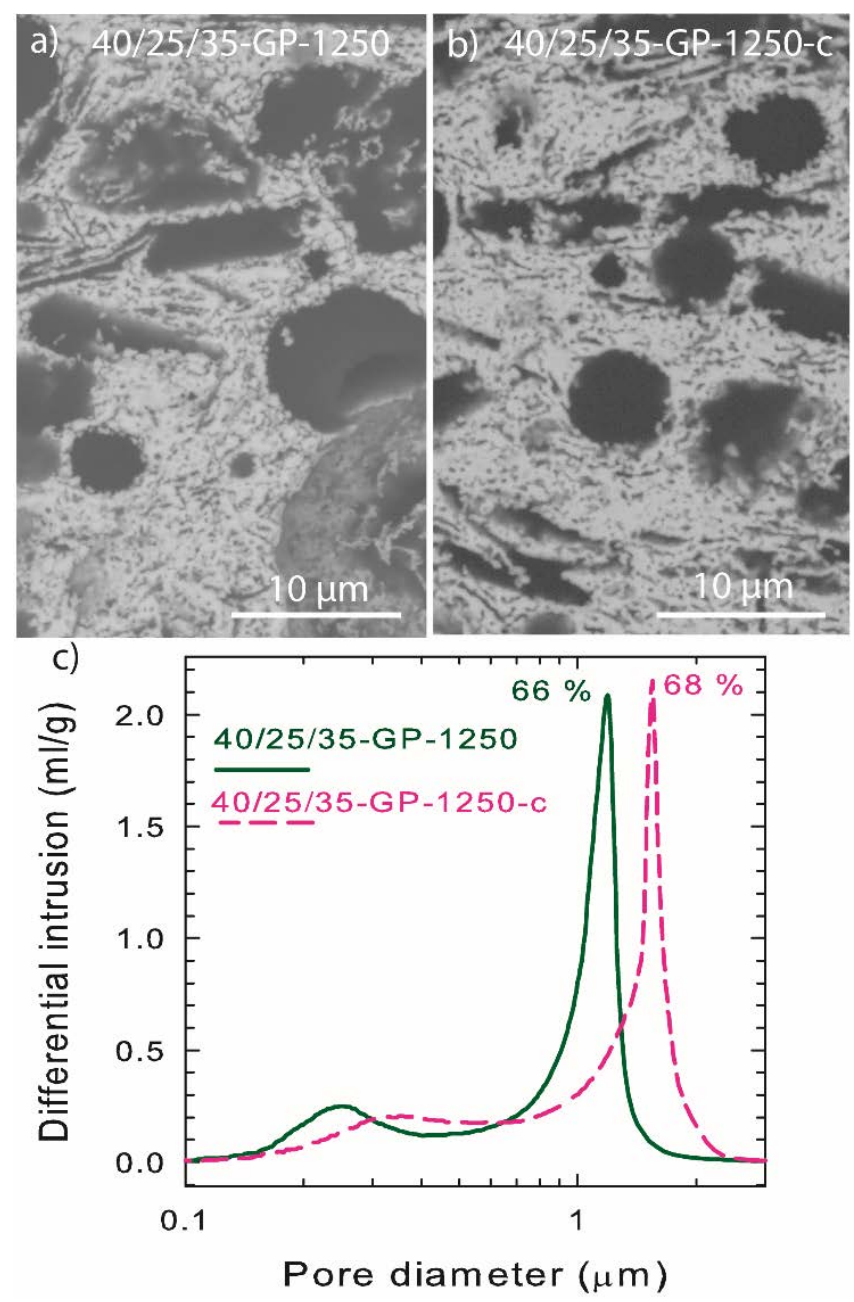

Fig. 5: Effect of 3Y-TZP particle size on microstructure and pore size distribution in porous 3YTZP. Micrographs of a) 40/25/35-GP-1250 and b) 40/25/35-GP-1250-c made with coarser 3Y-TZP 
powder. c) Porosimetry of the samples in a-b. The open porosity is written above the peak of each sample.

\subsection{Implementation of results for thermoplastic extrusion of 3Y-TZP support tubes}

The studies on thermoplastic feedstocks presented so far were performed on small disc samples prepared by warm pressing and sintering. It is important to investigate if the same properties are retained in larger batches during extrusion of thin-walled 3Y-TZP tubes. Fig. 6a-b show the microstructure of extruded vs. warm pressed versions of the same feedstock. A uniform pore distribution was observed throughout the sample thickness, independent of processing method. With both techniques, there is also a tendency for the graphite pore formers to deform or orient such that its long axis is perpendicular to the warm pressing axis and parallel to the extrusion direction. However, extrusion causes less deformed pores - observed in cross-sections both parallel and perpendicular to the extrusion direction - and the extruded samples appear more porous than the warm pressed. This is reflected in the accompanying porosimetry measurements (Table 1): extrusion provides slightly higher porosity and pore size compared to warm pressing. In accordance with the small microstructural differences, we observe slightly higher gas permeability in these extruded tubes compared to the warm pressed discs. This demonstrates that a screw extruder is suitable for extrusion of such porous supports. Piston extruders, operating at higher pressures, ${ }^{6}$ might have a slightly different effect on the pore morphology. It is also apparent from the microstructure that the conditions during warm pressing and extrusion are slightly different, which should be kept in mind when using warm pressing as a screening tool for pore former-containing thermoplastic feedstocks for extrusion.
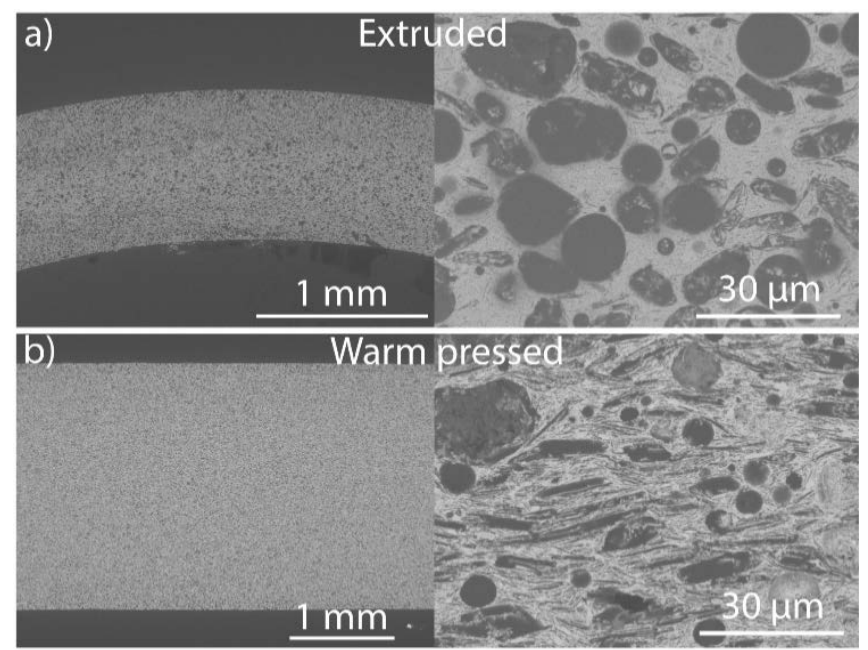
Fig. 6. Comparison of extruded and warm pressed porous support cross-sections. Micrographs of sample 45/25/30-GP-1250 as a) extruded tube, and b) as warm pressed disc.

Table 1. Effect of shaping type on 3Y-TZP support properties.

\begin{tabular}{lcccc}
\hline Feedstock & \multicolumn{2}{c}{$\mathbf{4 0 / 3 0 / 3 0 - G P - 1 2 5 0}$} & \multicolumn{2}{c}{$\mathbf{4 5 / 2 5 / 3 0 - G P - 1 2 5 0}$} \\
\hline & Warm pressed & Extruded & Warm pressed & Extruded \\
Open porosity (\%) & 60 & 62 & 65 & 66 \\
Pore size, dv50 ( $\mathbf{m m})$ & 0.52 & 0.76 & 0.69 & 0.99 \\
Gas permeability & $3.7 * 10^{-15}$ & $4.6 * 10^{-15}$ & $9.1 * 10^{-15}$ & $1.3^{*} 10^{-14}$ \\
$\mathbf{( m}^{\mathbf{2}}$ & & & & \\
\hline
\end{tabular}

\subsection{General discussion}

Highly porous and permeable 3Y-TZP supports have successfully been prepared, several with gas permeability above the $10^{-14} \mathrm{~m}^{2}$ target. This demonstrates that our thermoplastic feedstocks are suitable for fabrication of porous supports for oxygen transport membranes, as well as other technologies requiring macro-porous 3Y-TZP ceramics.

The trends in gas permeability observed experimentally between the different feedstocks are to a large extent also found in their corresponding permeability calculated according to Eqn. 1 (Fig. 7). The calculated permeability is higher with PMMA and graphite combined, compared to each pure pore former. The calculated permeability also increases with increasing pore former content and coarser YSZ powder, while the effect of the sintering temperature is small in the relevant cosintering range of 1250 to $1400{ }^{\circ} \mathrm{C}$. The measured gas permeability is $72 \%$ of the calculated averaged for all samples. The lower experimental value relative to the capillary permeability model $^{11}$ comply with our pore network being more tortuous than the parallel cylinders assumed in Eqn.1. Furthermore, the large size difference between the pore bottleneck size ( $d_{v 50}$ of $\left.\sim 1 \mu \mathrm{m}\right)$ and the actual pore diameter $(5-20 \mu \mathrm{m})$, also causes an overestimation of the "effective" pore volume actually contributing to the gas transport. ${ }^{21}$ The samples with PMMA as the only pore former causes the largest deviations from the model, possibly due to their more dispersed pore size distribution and therefore a larger difference between the $\mathrm{d}_{\mathrm{v} 50}$ used in the calculation and the actual pore sizes. 


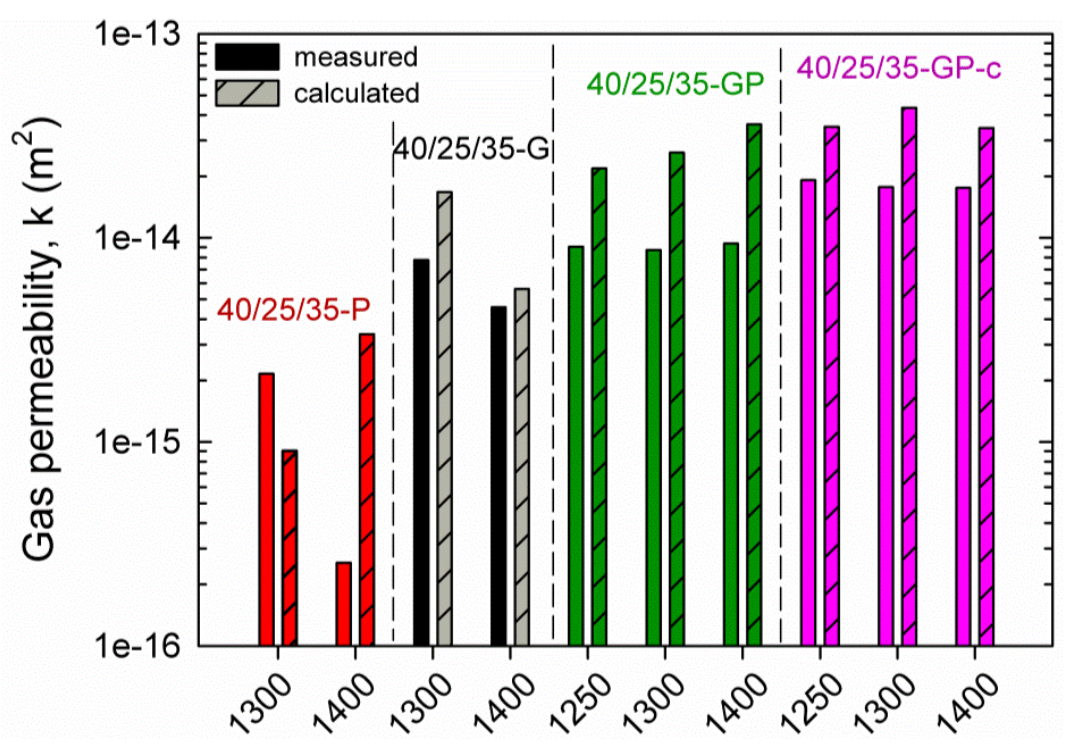

Fig. 7. Gas permeability as measured (plain columns) and calculated (stripy columns) according to Eqn. 1 for different feedstocks for porous 3Y-TZP ceramics, sintered at the temperature (in ${ }^{\circ} \mathrm{C}$ ) indicated below each pair of columns.

We initially stated that a gas permeability of $10^{-14} \mathrm{~m}^{2}$ was the target for our porous 3Y-TZP supports. Such gas permeability can be obtained e.g. with porosity $>40 \%$ and a pore size $>1 \mu \mathrm{m}$ (by Hg porosimetry) according to Eqn. 1. Obtaining more than $40 \%$ porosity was not a challenge. The open porosity increases as expected with the pore former content (Fig. 2d) and reached values up to 68 \% in sample 40/25/35-GP-1250-c. The pore sizes measured by Hg porosimetry, however, are in general lower than our initial target of $1 \mu \mathrm{m}$, due to the formation of narrow pore necks between the large pores. Increasing the support's pore size rather than the porosity should therefore be the target for future development of thermoplastic feedstocks for porous 3Y-TZP supports. Forming large pore necks appear to be a general challenge when using pyrolyzable pore formers; ${ }^{21}$, ${ }^{22}$ novel pore forming approaches in combination with thermoplastic feedstocks should therefore be investigated. Increasing the particle size of the 3Y-TZP powder showed promising results, including a fraction of even coarser powders could hence further improve the gas permeability. At the same time, care must be taken to retain the shrinkage during sintering such that stresses and defects from shrinkage mismatch between the support tube and the functional layers during co-firing of an asymmetric OTM are avoided. Using a mixture of $30 \%$ fine and $70 \%$ coarse $\mathrm{Ba}_{0.5} \mathrm{Sr}_{0.5} \mathrm{Co}_{0.8} \mathrm{Fe}_{0.2} \mathrm{O}_{3}$ d powder has provided large pores $(\sim 6 \mu \mathrm{m})$ and sufficient porosity (31 \%) in a solvent-based extrusion feedstock, although the shrinkage during sintering of these supports are not reported. ${ }^{12}$ Initial studies of the extruded supports' mechanical strength indicate the expected decrease in 
flexural strength with porosity, but $50 \mathrm{MPa}$ appears to be within reach for several compositions. A thorough study of the effect of feedstock composition, e.g. type and amount of pore formers, on tubular 3Y-TZP porous support strength will be the topic of further investigations.

Compared to previously extruded support tubes using thermoplastic feedstocks with pyrolyzable pore formers ${ }^{9,23}$ we have increased the gas permeability by an order of a magnitude. This can mainly be ascribed to a higher pore former load that could be applied in our thermoplastic feedstock without the feedstocks being too dry for extrusion. The low feedstock viscosity using PMMA as pore former indicates that PMMA adsorbs less thermoplastic polymer compared to graphite. In feedstocks with both graphite and PMMA pore formers, their ratio can be adjusted slightly to regulate the feedstock viscosity and improve the extrudability. Another considerable advantage of using graphite and combining it with PMMA as pore former is the low dependence of gas permeability of these 3Y-TZP thermoplastic feedstocks (in the relevant temperature range of 1250$140{ }^{\circ} \mathrm{C}$ ). When co-sintering the green $3 \mathrm{Y}$-TZP support tube with additional membrane layers, this insensitivity allows for a modification of the sintering cycle in order to e.g. optimize the densification of different membrane layers, without compromising the gas permeability of the support.

\section{Conclusion}

Thermoplastic feedstocks suitable for extrusion of porous 3Y-TZP support tubes for oxygen transport membranes have been developed. For this purpose, a large number of feedstocks have been screened to establish the effect of pore former content and type, 3Y-TZP particle size and sintering temperature on microstructure, porosity and gas permeability. The combination of a spherical type of graphite and polymethyl methacrylate (PMMA) as pore formers allowed to increase the pore former content to above 40 vol.\%, while still retaining a suitable viscosity for extrusion. Using these large amounts of graphite and PMMA pore formers, we could extrude and sinter 3Y-TZP tubes with a gas permeability of $10^{-14} \mathrm{~m}^{2}$. This permeability was relatively insensitive to the sintering temperature in the range $1250-1400^{\circ} \mathrm{C}$, which is highly advantageous for co-firing of the porous support with functional oxide membrane layers. Even in these highly porous 3Y-TZP tubes, the gas permeability is still limited by narrow pore necks between the large pores from the pore formers. The further development of thermoplastic feedstocks for the fabrication of porous supports should therefore focus on special techniques to widen these pore necks. 


\section{Acknowledgements}

The authors would like to thank Dr. Dhavanesan Kothanda Ramachandran for initial guidance on the thermoplastic feedstock system, and Pernille Hedemark Nielsen and Marianne Nielsen for assistance with feedstock preparation and porosimetry measurements. Energinet.dk is acknowledged for financial support through project 12202 "Ceramic membranes for oxy-fired biomass gasification”.

\section{References}

$1 \quad$ Y. Wei, W. Yang, J. Caro, and H. Wang, "Dense ceramic oxygen permeable membranes and catalytic membrane reactors,” Chem. Eng. J., 220 185-203 (2013). H.J.M. Bouwmeester and P.J. Gellings, Handbook of Solid State Electrochemistry. CRC Press, 1997. S. Baumann, W.A. Meulenberg, and H.P. Buchkremer, "Manufacturing strategies for asymmetric ceramic membranes for efficient separation of oxygen from air,” J. Eur. Ceram. Soc., 33 [7] 1251-1261 (2013). Y. Zhou, M. Fukushima, H. Miyazaki, Y. Yoshizawa, K. Hirao, Y. Iwamoto, and K. Sato, "Preparation and characterization of tubular porous silicon carbide membrane supports,” J. Memb. Sci., 369 [1-2] 112-118 (2011).

U. Pippardt, J. Böer, L. Kiesel, R. Kircheisen, R. Kriegel, and I. Voigt, “Co-firing technology for the preparation of asymmetric oxygen transporting membranes based on BSCF and Zr-doped BSCF,” AIChE J., 60 [1] 15-21 (2014).

F. Clemens, “Thermoplastic Extrusion for Ceramic Bodies;” pp. 295-311 in Extrus. Ceram. Edited by F. Händle. Springer-Verlag, Berlin, 2009.

M. Trunec, J. Cihlar, S. Diethelm, and J. Herle, "Tubular $\mathrm{La}_{0.7} \mathrm{Ca}_{0.3} \mathrm{Fe}_{0.85} \mathrm{Co}_{0.15} \mathrm{O}_{3 \text {-delta }}$ Perovskite Membranes, Part I: Preparation and Properties,” J. Am. Ceram. Soc., 89 [3] 949-954 (2006). M. Salehi, E.M. Pfaff, R.M. Junior, C.P. Bergmann, S. Diethelm, C. Neururer, T. Graule, B. Grobéty, et al., " $\mathrm{Ba}_{0.5} \mathrm{Sr}_{0.5} \mathrm{Co}_{0.8} \mathrm{Fe}_{0.2} \mathrm{O}_{3-\delta}$ (BSCF) feedstock development and optimization for thermoplastic forming of thin planar and tubular oxygen separation membranes,” J. Memb. Sci., 443 237-245 (2013). sacrificial fugitives in thermoplastic extrusion feedstocks on properties of MgO supports for oxygen transport membranes,” J. Eur. Ceram. Soc., 35 [5] 1527-1537 (2015). 
Ramachandran, D.W. Ni, et al., "Design and optimization of porous ceramic supports for asymmetric ceriabased oxygen transport membranes,” J. Memb. Sci., 513 85-94 (2016).

T. Ohji and M. Fukushima, “Macro-porous ceramics: processing and properties,” Int. Mater. Rev., 57 [2] 115131 (2012).

M. Schulz, U. Pippardt, L. Kiesel, K. Ritter, and R. Kriegel, “Oxygen permeation of various archetypes of oxygen membranes based on BSCF,” AIChE J., 58 [10] 3195-3202 (2012).

J. Gurauskis, S. Ovtar, A. Kaiser, M. Sogaard, and P. V. Hendriksen, “Ceria Based Composite Membranes for Oxygen Separation,” ECS Trans., 64 [2] 251-258 (2014).

J.J. Martin, M.S. Riederer, M.D. Krebs, and R.M. Erb, “Understanding and overcoming shear alignment of fibers during extrusion,” Soft Matter, 11 400-405 (2015).

G.L. Messing, E.M. Sabolsky, S. Kwon, and S. Trolier-McKinstry, Templated Grain Growth of Textured Piezoelectric Ceramics. 2002.

6 D.K. Ramachandran, M. Søgaard, F. Clemens, B.R. Sudireddy, and A. Kaiser, "Low cost porous MgO substrates for oxygen transport membranes,” Mater. Lett., 169 254-256 (2016).

M. Wegmann, F. Clemens, A. Hendry, and T. Graule, "Dispersion of lanthanoid-coated barium titanate in a paraffin-based extrusion binder system,” Ceram. Int., 32 [2] 147-156 (2006).

M. Salehi, F. Clemens, E.H. Otal, D. Ferri, T. Graule, and B. Grobéty, “Debinding mechanisms in thermoplastic processing of a $\mathrm{Ba}_{0.5} \mathrm{Sr}_{0.5} \mathrm{Co}_{0.8} \mathrm{Fe}_{0.2} \mathrm{O}_{3-\delta}$ stearic acid-polystyrene mixture.," ChemSusChem, 6 [2] 336-44 (2013).

M. Trunec and J. Cihlar, “Thermal removal of multicomponent binder from ceramic injection mouldings,” $J$. Eur. Ceram. Soc., 22 [13] 2231-2241 (2002).

H. Giesche, “Mercury Porosimetry: A General (Practical) Overview,” Part. Part. Syst. Charact., 23 [1] 9-19 (2006).

D. Simwonis, A. Naoumidis, F.J. Dias, J. Linke, and A. Moropoulou, "Material characterization in support of the development of an anode substrate for solid oxide fuel cells,” J. Mater. Res., 12 [06] 1508-1518 (2011).

A. Sanson, P. Pinasco, and E. Roncari, "Influence of pore formers on slurry composition and microstructure of tape cast supporting anodes for SOFCs,” J. Eur. Ceram. Soc., 28 [6] 1221-1226 (2008).

D.K. Ramachandran, F. Clemens, A.J. Glasscock, M. Søgaard, and A. Kaiser, “Tailoring the microstructure of porous MgO supports for asymmetric oxygen separation membranes: Optimization of thermoplastic feedstock systems,” Ceram. Int., 40 [7] 10465-10473 (2014). 


\section{Appendix}

Table A.1. All samples and their properties, sorted after type of pore former or 3Y-TZP powder. All samples are named as “composition” (vol\% pore former / vol\% ceramic /vol\% polymer) - “pore former” (G for graphite, P for PMMA, GP for both (volume ratio 2:1 unless otherwise stated)) - "sintering temperature" $\left({ }^{\circ} \mathrm{C}\right)$

\begin{tabular}{|c|c|c|c|c|c|c|}
\hline Sample & $\begin{array}{l}\text { Torque } \\
(\mathrm{Nm})\end{array}$ & $\begin{array}{l}\text { Shrinkage } \\
\text { (\%) }\end{array}$ & $\begin{array}{l}\text { Total } \\
\text { porosity } \\
\text { (\%) }\end{array}$ & $\begin{array}{l}\text { Open } \\
\text { porosity } \\
(\%)\end{array}$ & $\begin{array}{l}\text { Pore } \\
\text { size, } \\
d_{v 50} \\
(\mu \mathrm{m})\end{array}$ & $\begin{array}{l}\text { Gas } \\
\text { permeability } \\
\left(\mathrm{m}^{2}\right)\end{array}$ \\
\hline \multicolumn{7}{|c|}{ Graphite and PMMA as pore formers, in the volume ratio 2:1 } \\
\hline 23/35/42-GP-1300 & 2.5 & 27 & 40 & 29 & 0.33 & N/A \\
\hline 23/35/42-GP-1400 & 2.5 & 27 & 36 & 26 & 0.50 & N/A \\
\hline 30/35/35-GP-1300 & 4.5 & 23 & 49 & 38 & 0.51 & 3.7E-15 \\
\hline 30/35/35-GP-1400 & 4.5 & 25 & 45 & 33 & 0.67 & $1.7 \mathrm{E}-15$ \\
\hline 35/35/30-GP-1300 & 8.0 & 21 & 51 & 45 & 0.51 & 3.5E-15 \\
\hline 35/35/30-GP-1400 & 8.0 & 23 & 46 & 38 & 0.67 & $3.4 \mathrm{E}-15$ \\
\hline 35/30/35-GP-1300 & 5.5 & 23 & 54 & 51 & 0.66 & $2.8 \mathrm{E}-15$ \\
\hline 35/30/35-GP-1400 & 5.5 & 26 & 51 & 41 & 0.79 & $4.2 \mathrm{E}-15$ \\
\hline 23/42/35-GP-1300 & 4.0 & 23 & 39 & 29 & 0.26 & $1.0 \mathrm{E}-15$ \\
\hline 23/42/35-GP-1400 & 4.0 & 24 & 38 & 24 & 0.32 & $1.2 \mathrm{E}-15$ \\
\hline 40/25/35-GP-1250 & 6.7 & 16 & 69 & 66 & 1.03 & $9.0 \mathrm{E}-15$ \\
\hline 40/25/35-GP-1300 & 6.7 & 19 & 66 & 66 & 1.13 & 8.7E-15 \\
\hline 40/25/35-GP-1400 & 6.7 & 23 & 61 & 60 & 1.39 & $9.4 \mathrm{E}-15$ \\
\hline 40/30/30-GP-1250 & 11.2 & 15 & 66 & 59 & 0.52 & $3.7 E-15$ \\
\hline 40/30/30-GP-1300 & 11.2 & 15 & 65 & 61 & 0.74 & $1.1 \mathrm{E}-14$ \\
\hline 40/30/30-GP-1400 & 11.2 & 21 & 56 & 55 & 0.86 & 7.3E-15 \\
\hline 45/25/30-GP-1250 & 13.0 & 16 & 71 & 65 & 0.69 & $9.1 \mathrm{E}-15$ \\
\hline 45/25/30-GP-1300 & 13.0 & 15 & 70 & 66 & 0.87 & $1.7 \mathrm{E}-14$ \\
\hline 45/25/30-GP-1400 & 13.0 & 22 & 61 & 55 & 0.97 & $9.8 \mathrm{E}-15$ \\
\hline \multicolumn{7}{|c|}{${ }^{*}$ Graphite and PMMA as pore formers, in the volume ratio $1: 2$} \\
\hline 40/30/30-GP*-1300 & 7.2 & 20 & 46 & 45 & 0.49 & $1.3 \mathrm{E}-15$ \\
\hline $40 / 30 / 30-G P *-1400$ & 7.2 & 20 & 51 & 49 & 0.86 & 4.7E-15 \\
\hline $45 / 25 / 30-G P *-1300$ & 9.9 & 21 & 56 & 54 & 0.71 & $4.2 \mathrm{E}-15$ \\
\hline 45/25/30-GP*-1400 & 9.9 & 21 & 59 & 54 & 1.14 & $1.1 \mathrm{E}-14$ \\
\hline \multicolumn{7}{|c|}{${ }^{* *}$ Graphite and PMMA as pore formers, in the volume ratio 1:1 } \\
\hline $40 / 30 / 30-G P^{* *}-1300$ & 9.8 & 19 & 50 & 56 & 0.53 & $2.2 \mathrm{E}-15$ \\
\hline $40 / 30 / 30-G P * *-1400$ & 9.8 & 23 & 54 & 42 & 0.65 & $2.1 \mathrm{E}-15$ \\
\hline $45 / 25 / 30-G P * *-1300$ & 9.9 & 20 & 59 & 59 & 0.72 & $6.2 \mathrm{E}-15$ \\
\hline
\end{tabular}




\begin{tabular}{lcccccc} 
45/25/30-GP**-1400 & 9.9 & 25 & 58 & 50 & 0.85 & $5.7 \mathrm{E}-15$ \\
\hline PMMA as pore former & & & & & & \\
40/25/35-P-1300 & 3.5 & 23 & 55 & 36 & 0.29 & $2.2 \mathrm{E}-15$ \\
40/25/35-P-1400 & 3.5 & 28 & 48 & 31 & 0.42 & $2.6 \mathrm{E}-16$ \\
\hline Graphite as pore former & & & & & \\
40/25/35-G-1300 & 11.0 & 19 & 69 & 60 & 0.75 & $7.8 \mathrm{E}-15$ \\
40/25/35-G-1400 & 11.0 & 25 & 59 & 48 & 0.75 & $4.6 \mathrm{E}-15$ \\
\hline Graphite and PMMA (2:1) as pore formers, coarser YSZ powder & 62 & 68 & & 1.28 & $1.9 \mathrm{E}-14$ \\
40/25/35-GP-1250-c & 9.5 & 16 & 62 & 67 & 1.44 & $1.8 \mathrm{E}-14$ \\
40/25/35-GP-1300-c & 9.5 & 20 & 52 & 46 & 1.55 & $1.8 \mathrm{E}-14$ \\
40/25/35-GP-1400-c & 9.5 & 25 & & &
\end{tabular}

